\title{
Practical Work at the Open University of the Netherlands
}

\author{
Marthie A. M. Meester ${ }^{1}$ and Paul A. Kirschner ${ }^{2,3}$
}

\begin{abstract}
Achieving practical objectives in an open distance educational system is a real challenge. Its philosophy requires self-instructional materials that students can study at their own time, place, and pace. Practical work, in particular laboratory work, can test the limits of this philosophy. A new way of thinking about practical work and modern electronic media make it possible to develop a natural sciences degree program with a minimum amount of laboratory sessions and, hopefully, to pursue practical aims which are useful in the student's later profession. The way the Open University of the Netherlands has been developing a practical program according to these starting points is discussed in the first part of this paper. Examples of alternatives for traditional practical work are described in more detail in the second part. Advantages and disadvantages with regards to traditional practical work are discussed.
\end{abstract}

KEY WORDS: Practicals; laboratories; natural sciences; Open University; distance education; electronic media.

\section{PRACTICALS IN NATURAL SCIENCES AT THE OPEN UNIVERSITY OF THE NETHERLANDS}

\section{Open University of the Netherlands: Open Distance Education}

The Open University of the Netherlands (OUN) is an institution for open, higher, distance education. The open quality is characterized by open admission, open programming, and open pace of study. Open admission means that there are no formal entry requirements for students. Admission does not depend on having received a diploma from a conventional secondary or tertiary institute, as is the

\footnotetext{
${ }^{1}$ Department of Natural Sciences, Open University of the Netherlands, P.O. Box 2960, 6401 DL Heerlen, The Netherlands.

${ }^{2}$ Educational Technology Innovation Centre, Open University of the Netherlands, P.O. Box 2960, 6401 DL Heerlen, The Netherlands.

${ }^{3}$ Correspondence should be directed to Paul A. Kirschner, Educational Technology Innovation Centre, Open University of the Netherlands, P.O. Box 2960, 6401 DL Heerlen, The Netherlands.
}

case for traditional universities and vocational colleges. This does not mean that there is no prerequisite knowledge required for the successful completion of a course, nor does it mean that the level of the courses is lower than that of other institutions for higher learning. The only restriction is that a student must be at least 18 years old to enroll. Thus the OUN is also an institute for adult education. Open programming means that students are given the freedom to compose their own study programs, within certain limits, and may interrupt their studies with a minimum of problems. Open pace of study means that students are free to adapt their pace of study to their own needs. In practical terms, this means that students can begin a course whenever they wish. This also means that they should be allowed to complete a course, usually by sitting an examination, whenever they wish. The only restriction is that they must do this within one year of subscribing to the course. There are no semesters, academic years, or summer vacations.

That it is an institution for distance education means that the OUN has no residential students and 
does not rely on direct teacher-student (face-toface) contact for the transmission of knowledge and skills. The OUN strives, rather, to use their media and didactic techniques to make studying as independent as possible of time and place (Wolf, 1985). In practice, this means that students should be able to study wherever and whenever they wish. The OUN should, for its part, do its best not to require them to be at a certain place at a certain time.

The aims of this new form of education in the Netherlands are formulated in a policy paper entitled Open Universities in the Netherlands (Nota, 1979), which was presented to the Dutch parliament in the spring of 1979. These aims are:

- To bring higher education within the reach of those who, for whatever reason, have not had access to it (second chance education);

- to enable those people to study who are not in the position to receive higher education in any other form (second way education);

- to encourage innovation in both full-time and part-time education with respect to both form (didactics and use of technology) and content (multi- and interdisciplinary programs); and

- to provide a less expensive form of higher education than traditional higher education (university and higher vocational).

\section{Natural Sciences at OUN}

Very few scientists will dispute the proposition that practicals are an integral and indispensable part of a program in the natural sciences, but there are two issues that make this stance problematic. First practicals are very expensive, both in time (for students and staff) and in money (salaries, buildings, apparatus, and materials). Second, and more important, practicals although indispensable for achieving some selected objectives, primarily psychomotor objectives, are not very efficient or effective for achieving all of the different objectives educators tend to ascribe to them. Over the last 15 years many critical articles have been written about the effectiveness and efficiency of practical work, in particular laboratory work (Hofstein and Lunetta, 1982; Toothacker, 1983; Hodson, 1988, 1992; Kirschner and Meester, 1988; Clackson and Wright, 1992). One of the main criticism is that practical work is neither used nor designed to achieve those aims for which it is most appropriate, namely the achievement of certain cognitive academic skills.

The philosophy and policy of the OUN of open, interdisciplinary distance education puts these criticisms in a particular perspective, but this perspective also means extra problems:

- The open character of the OUN, which offers students the freedom to determine their own time, pace, and place of study, requires that the necessity to be at a certain place at a certain time in a certain phase of study be kept to an absolute minimum. Compulsory attendance (e.g., a laboratory) is permissible in the OUN's philosophy and policy only if these is no other didactic alternative.

- The OUN does not offer a monodisciplinary degree program where a student can become a biologist, a chemist or a physicist. If offers multidisciplinary or interdisciplinary programs such as environmental sciences, nutrition and toxicology, and environmental policy and management. As a result, practical work at the Open University has different goals and a less prominent place than it has at more traditional universities. Nevertheless, practicals are important at the Open University too.

This perspective calls for a reevaluation of the objectives for undergraduate practicals in higher natural sciences education with extra emphasis on the effectiveness and efficiency of teaching methods used to achieve those aims.

In order to arrive at a situation that was optimal from an educational perspective as well as from the OUN's specific needs, the staff members of the faculty of natural sciences at the OUN were surveyed to define which practical objectives the faculty members themselves felt the students should meet in their science degree programs (Kirschner et al., 1991). Next, based upon the results of this survey, the effective and efficient implementation and integration of a different type of practicals in the different OUN courses took place. Finally, first- and second-level integrated courses on experimentation were developed as a replacement for discipline-specific practicals which were being used at that moment.

In this paper we will first discuss the practical component in the degree programs of the OUN, 
have a closer look at two courses on experimentation, and finish with some examples of alternatives for traditional practical work (labs). Before starting the practical component, we have to convey our definition of practical work and the different educational media we have at our disposal.

\section{Some Definitions}

Practical work and laboratory work are not equivalent. The idea that a practical is nothing more than laboratory benchwork or experimental work has to be broadened. A proper definition would also have to take into account that the OUN has chosen to educate a different type of natural scientist in an education setting that does not include residential students or class room sessions.

The laboratory, used as a didactic method in education, may be defined as "contrived learning experiences in which students interact with materials to observe phenomena in a laboratory classroom" (Hofstein and Lunetta, 1982). The experiments often turn out to be cookbook experiments in which students only have to follow a recipe. A practical, on the other hand, is a didactic method for learning and practicing all the activities involved in carrying out one's profession. Within higher education and primarily in the natural sciences, this professional practice entails experimental work, beginning with the conception of a problem or the observation of a phenomenon to the communication of results in the form of a report or an oral presentation (Kirschner et al., 1991). Hodson (1988) presents this relationship as follows: experimental work is a subset

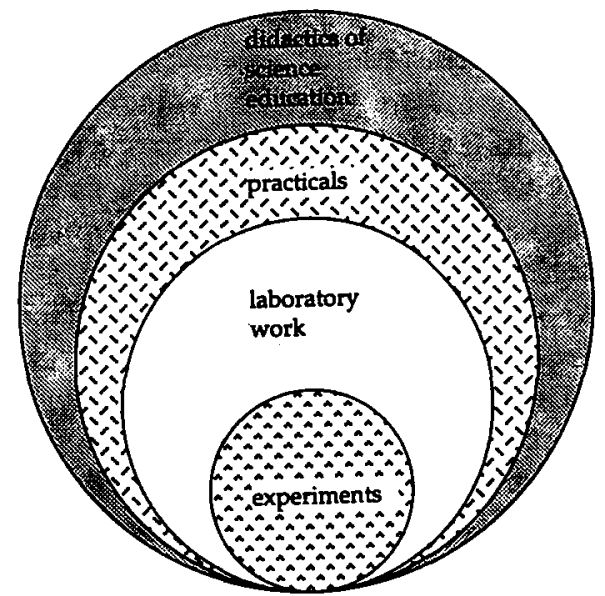

Fig. 1. The interrelationship between experiments, laboratory work, and practicals (Hodson, 1988). of laboratory work. Laboratory work or, as he calls it, laboratory benchwork in turn is a subset of practicals, which in turn is a subset of the didactics of science education (Fig. 1).

The most commonly heard motives for implementing practicals in a natural sciences curriculum seem to be based upon the premise that practicals should be used for the illustration, confirmation, acquisition, or discovery of the substantive structure of science. The motives are that: (1) the value of a practical lies in its service or subservience to scientific theory; (2) the practical, due to its reliance upon discovery, is the best if not the only way to achieve meaningful learning in the natural sciences; and (3) through the use of empirical work in practicals, the learner will distill insight and understanding in natural phenomena and the laws governing their behavior.

In our opinion better motives for using practicals are: (1) teaching/learning specific skills (e.g., observation, measurement, estimation, manipulation, planning, hypothesizing, interpretation); (2) teaching/learning the academic approach to how to work as a scientist; and (3) providing students with experiences of real phenomena through which they may gain a certain tacit knowledge of these phenomena.

The first motive is that practicals are best suited to helping develop specific skills. A type of practical that is well suited to the attainment of this first motive because of its use of both practice and feedback is simulation. Educational simulation programs are "interactive learning environments in which a model simulates characteristics of a system, depending on actions made by the student" (Huisman and De Vries, 1991). In educational simulations guidance also plays an essential role.

The second motive is that practicals are suitable vehicles for learning the "academic approach" to working (especially as a scientist). The experimental seminar, because of its use of discussion, is well suited for the achievement of the second motive. In experimental seminars, an approach for undergraduate students in natural sciences first proposed by Conway et al. (1963), students cooperate in the performance of an experiment collectively or by watching an expert perform an experimental. This way they may gain a clear concept of how a well-performed experiment progresses. Collective experimentation or demonstration is followed by group discussion, stimulated, where necessary, by an ex- 
pert, such as teacher, lecturer, or professor, and in which students can help each other. An experiment that is routine and uninteresting to one or two students can trigger a valuable discussion in a group. This provides the student with a model for problem identification, experimental design, assembling, testing and calibrating equipment, data collection, analysis, interpretation, and reporting results. The possibility to model, discuss, reason, and compare methods and results with others is characteristic for this type of practical.

The third motive for implementing practicals in science curricula is to allow students to experience phenomena and all that accompanies such phenomena, and in doing so to gain a tacit knowledge of different scientific phenomena and their settings. The appropriate practical for this motive is, thus, the traditional practical which is often referred to as the "wet laboratory."

In this light, the OUN has decided not to limit its practicals to laboratory work. Any activity relating to learning the process of experimentation, such as demonstrations, computer simulations, real laboratory work, paper-and-pencil experiments, videotapes, or CD-ROM, all counts as practical work, because one can achieve some practical objectives with these didactic methods.

\section{Choice of Media}

Being an institution for distance education, the central didactic principle underlying the OUN is that of guided self-study. Education aimed at self-study is highly dependent on the lay out and presentation of the study materials.

The OUN has at its disposal several different educational media that are applied depending on the aims of the educational process. These media, in decreasing order of options, are printed materials, electronic media (audio, computer, video, and so forth), and the tutor as medium (which also includes the wet laboratory for natural sciences). By far the most widely used medium is printed material. This material either has to be specially written for distance education or consists of already-existing printed materials (handbooks, textbooks, etc.) that have to be adapted to meet the needs of distance education. This can be achieved by a variety of didactic techniques such as the explication of learning objectives and the use of key words, margin texts, study instructions in text questions and self-assess- ment tests. Although certain cognitive skills can be acquired solely through the use of printed materials, it is difficult with this medium alone to achieve more practical skills.

Often complementing the printed material in a distance setting are simple or linear electronic media (telephone, radio, and broadcast television) to achieve objectives that the printed word cannot, such as bringing the expert to the student and demonstrating chemical or physical phenomena. These linear media, however, are used in a passive way by students-they have only to view or listen-and as such were never a large part of the OUN's media mix. The more modern interactive electronic media give new opportunities to obtain learning objectives that are not feasible with linear media. Examples are computers, interactive video (IV) disk, compact disk-read only memory (CD-ROM), and compact disk interactive (CD-I). An educational IV or CD-I program consists of a video or compact disk controlled by students via a computer-assisted learning (CAL) program.

The question now arises as to when the OUN uses these electronic media. Here one should distinguish between the use of such media in a substantive sense and use of the media in a supportive sense. Audio, for instance, may be used to expose the students to a discussion or samples of "real-life phenomena." In such a case it is used substantively, as an alternative, but indispensable, channel for conveying educational material. The medium, its semantics, and its semiotic or symbol system itself is the topic of study. Audio may, on the other hand, also be used to give students feedback on a paper or project they have completed or to talk a student through a diagram or scheme. In this way it is used to support the educational process, and the media used is only a means. Similarly, computers may be used either to teach students how to work with particular programs (data base, word processor, statistical package) or to simulate a particular experimental set-up or a phenomenon in a CAL program. The former is substantive use, the latter supportive. In our educational system, we use these new media primarily in a supportive way. Further on in this paper, we will describe a course on remote sensing in which CD-ROM is used substantively.

Although in computer simulations and IV and CD-I programs genuine manipulative (motor) skills may not be practiced, the practical procedures themselves can be rehearsed (Moore et al., 1980). Stu- 
dents can make observations, collect and interpret experimental data, and make appropriate decisions in order to complete the experiment correctly. In this way, they facilitate laboratory performances, increase the general efficiency and effectiveness of instruction, and can be used for simulations of biological, chemical, and physical phenomena that are not, or often cannot be, demonstrated or experienced in a laboratory setting. The advantage of IV and CD-I programs over computer simulation is the use of moving and real-life images and, therefore, it is especially useful for bringing specific realities to the student and for designing and carrying out of processes and real-life situations.

If certain learning objectives cannot be conveyed by either of the two previous types of media, as is the case of practical work aimed at achieving manipulative objectives, then the Open University

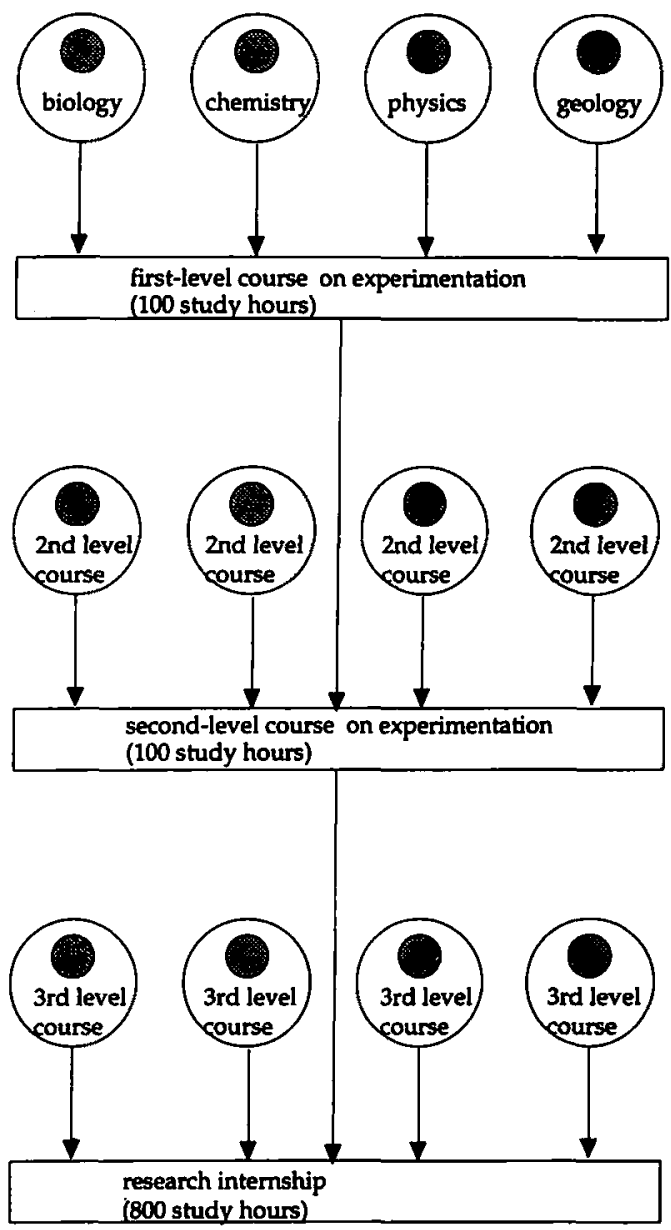

practical component for skills acquisition

Fig. 2. Practicals in the degree programs of natural sciences (Kirschner, 1992). does have a further option, namely, face-to-face teaching. This can be done in discussion groups, via wet laboratories, and by means of individual supervision using tutors in study centers.

\section{Practical Component in Degree Programs of OUN: A General View}

As already stated, a university study in the natural sciences devoid of a practical component is unthinkable. Nobody questions the necessity of practical work in natural sciences curricula, since practical work is simply a part of the science game. What is being questioned more and more, however, is how and to what extent students should make use of wet laboratories during their study. At traditional universities in the Netherlands, the different monodisciplinary natural sciences programs, such as chemistry, biology and physics, contain approximately 800-1000 hours of undergraduate practicals out of a total of about 5400 study hours (about $20 \%$ ). Apart from these curricular laboratory hours, roughly 1200 hours have been reserved for research training within experimental research projects, bringing the total to 2200 of the 6800 hours (about $35 \%$ ). At the Open University, while it was agreed that practicals in the natural science program were necessary, it was also agreed that these practicals should differ, both in quality (regarding to objectives, contents and methods) and in quantity from practicals at traditional universities. Practicals in the broader sense are incorporated in the degree programs of the OUN in several places, as can be seen in Fig. 2.

Practicals such as computer simulations and IV or CD-I programs function as a component of a specific course, whereas laboratory work is done in two courses on experimentation. The starting point in the study are the monodisciplinary firstlevel courses in biology, chemistry, geology, and physics, apart from courses in mathematics, informatics, and environmental sciences. Each of these courses has practicals meant for imparting basic academic skills to the students either with the aid of audiovisual media or with computer-based materials (computer simulations on regulation processes in the biology course; a video disk about NMR, IR, and separation techniques in the chemistry course; a CAL program about magnetic fields in the physics course; and an IV excursion through the Belgian Ardennes in the geology course). These 
Table I. Specific Leaming Objectives Divided across First- and Second-Level Courses on Experimentationa

\begin{tabular}{|c|c|c|c|c|c|c|c|}
\hline Specific objective & $\begin{array}{l}\text { General } \\
\text { objective }\end{array}$ & $\begin{array}{l}\text { First } \\
\text { level }\end{array}$ & $\begin{array}{l}\text { Second } \\
\text { level }\end{array}$ & Specific objective & $\begin{array}{l}\text { General } \\
\text { objective }\end{array}$ & $\begin{array}{l}\text { First } \\
\text { level }\end{array}$ & $\begin{array}{l}\text { Second } \\
\text { level }\end{array}$ \\
\hline $\begin{array}{l}\text { Solve difficult scientific problems by } \\
\text { decomposing them into smaller } \\
\text { problems } \\
\text { Solve problems in which there is more } \\
\text { than one usable solution strategy }\end{array}$ & $\mathbf{A}$ & $\mathbf{x}$ & 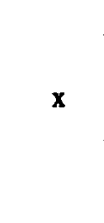 & $\begin{array}{l}\text { Be flexible with respect to modifying } \\
\text { experiments in light of results obtained } \\
\text { in prior experimentation } \\
\text { Keep a day-to-day laboratory diary in } \\
\text { such a way that a third person can } \\
\text { repeat the experiments }\end{array}$ & $\mathrm{D}$ & $\mathbf{x}$ & $\mathbf{x}$ \\
\hline $\begin{array}{l}\text { Derive and evaluate relationships between } \\
\text { observed scientific phenomena }\end{array}$ & $\mathbf{A}$ & & $\mathbf{x}$ & Process experimental data & $\mathbf{E}$ & $\mathrm{x}$ & $\mathbf{x}$ \\
\hline $\begin{array}{l}\text { Use experimental data to solve specific } \\
\text { problems } \\
\text { Understand the purpose of an experiment }\end{array}$ & $\begin{array}{l}\text { A } \\
\mathrm{A}\end{array}$ & $\begin{array}{l}\mathbf{x} \\
\mathbf{x}\end{array}$ & & $\begin{array}{l}\text { Analyze experimental data in order } \\
\text { to draw conclusions from them } \\
\text { Apply principles rather than rote use } \\
\text { of computational formulae in the } \\
\text { theoretical analysis of the lab } \\
\text { experiment }\end{array}$ & $\mathrm{E}$ & $\mathbf{x}$ & $\mathbf{x}$ \\
\hline $\begin{array}{l}\text { Understand what is too be measured } \\
\text { during an experiment } \\
\text { Identify the variables that adequately } \\
\text { describe some system's state and } \\
\text { empirically determine the way they } \\
\text { are related }\end{array}$ & $\mathbf{A}$ & $\mathbf{x}$ & 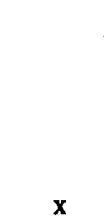 & $\begin{array}{l}\text { Apply elementary notions of statistics } \\
\text { in evaluating experimental data } \\
\text { Evaluate how errors in direct } \\
\text { measurements may contribute to } \\
\text { errors in a derived measure }\end{array}$ & $\mathbf{E}$ & $\mathbf{x}$ & $\mathbf{x}$ \\
\hline Derive testable hypotheses from theories & A & & $\mathrm{x}$ & $\begin{array}{l}\text { Evaluate the experimental data with } \\
\text { regard to the hypothesis or theory } \\
\text { being tested }\end{array}$ & $\mathbf{E}$ & $\mathbf{x}$ & $\mathbf{x}$ \\
\hline $\begin{array}{l}\text { Apply known principles and knowledge in } \\
\text { solving new problems }\end{array}$ & B & & $x$ & $\begin{array}{l}\text { Make order-of-magnitude calculations } \\
\text { and estimates within given precision }\end{array}$ & $\mathbf{E}$ & $\mathbf{x}$ & \\
\hline Recognize and define scientific problems & B & $\mathbf{x}$ & $\mathbf{x}$ & $\begin{array}{l}\text { Incorporate unexpected experimental } \\
\text { results in a new model }\end{array}$ & $\mathbf{E}$ & & $\mathbf{x}$ \\
\hline $\begin{array}{l}\text { Construct models based on experimental } \\
\text { findings }\end{array}$ & $\mathbf{B}$ & & $\mathbf{x}$ & $\begin{array}{l}\text { Use data already obtained to make } \\
\text { estimates regarding not yet tested } \\
\text { situations }\end{array}$ & $\mathbf{E}$ & & $\mathbf{x}$ \\
\hline $\begin{array}{l}\text { React adequately when confronted } \\
\text { with unforseen results }\end{array}$ & $\mathbf{B}$ & & $\mathbf{x}$ & $\begin{array}{l}\text { Interpret the reliability and meaning of } \\
\text { results gained through experimentation } \\
\text { (either their own or those of others) }\end{array}$ & $\mathbf{E}$ & $\mathbf{x}$ & $x$ \\
\hline $\begin{array}{l}\text { Design an experiment to test a theory } \\
\text { or hypothesis }\end{array}$ & $\mathrm{C}$ & & $\mathbf{x}$ & $\begin{array}{l}\text { Give a written description of the } \\
\text { essentials of an experiment based on } \\
\text { collected data }\end{array}$ & $\mathbf{F}$ & $\mathbf{x}$ & $\mathbf{x}$ \\
\hline $\begin{array}{l}\text { Properly plan an experiment } \\
\text { Design observation techniques relevant } \\
\text { to the task at hand }\end{array}$ & $\mathbf{C}$ & $\mathrm{x}$ & $\mathbf{x}$ & $\begin{array}{l}\text { Communicate experimental findings } \\
\text { in oral form } \\
\text { Suggest follow-up investigations once the } \\
\text { results of a scientific investigation } \\
\text { are known }\end{array}$ & $\mathbf{F}$ & $\mathbf{x}$ & $\mathbf{x}$ \\
\hline $\begin{array}{l}\text { Design subsequent experiments involving } \\
\text { the phenomena being tested }\end{array}$ & C & & $\mathbf{x}$ & $\begin{array}{l}\text { Discuss results of scientific investigations } \\
\text { with scientists }\end{array}$ & $\mathbf{F}$ & & $\mathbf{x}$ \\
\hline $\begin{array}{l}\text { Recognize hazards so as to take } \\
\text { appropriate safety precautions }\end{array}$ & C & $\mathbf{x}$ & & & & & \\
\hline $\begin{array}{l}\text { Understand the scope and limiting } \\
\text { conditions of the exprimental } \\
\text { techniques used }\end{array}$ & C & & $\mathbf{x}$ & & & & \\
\hline Understand laboratory instructions & D & $\mathbf{x}$ & & & & & \\
\hline Experiment safely & $\mathrm{D}$ & $\mathbf{x}$ & & & & & \\
\hline Observe phenomena in a qualitative way & $\mathrm{D}$ & $\mathbf{x}$ & & & & & \\
\hline Observe phenomena in a quantitative way & D & $\mathbf{x}$ & $\mathbf{x}$ & & & & \\
\hline
\end{tabular}

${ }^{a}$ In this table an ' $x$ ' denotes that an objective should be explicitly covered. If, for example, an objective has received an ' $x$ ' at the first level and not at the second, this means that it will be explicitly handled in the first-level course. The student will be expected to have mastered it so that it can be used as a tool in the second-level course. The objectives which have received an ' $x$ ' for both the first- and the second-level course are objectives that are considered to be either so important or so complex (or both) that they warrant being explicitly handled in both of the courses. The letters A-F indicate the general objectives to which the specific objectives belong (see Fig. 3). 
four courses are directly followed by the first-level course on experimentation. The main goal of this 100 -hour course is the acquisition of those basic academic skills that are characteristic for the different phases of experimentation in the natural sciences (Table I, third column).

Following the first-level course on experimentation, there are the second-level courses, which almost all have one or more practical components, of which some are real substitutions for wet laboratory work while others are not, but which all broaden the student's practical experience. Examples of wet laboratory alternatives are: a large CD-I determination practical on toxicological histopathology, which is part of the general toxicology course and computer and IV practicals on population dynamics and animal behavior, which form part of the biology of populations and behavior course. On the other hand, practical work that does not replace wet laboratory work can be found in the course on mathematical modelling in the life sciences. In this course students learn to model such diverse processes as enzyme kinetics, tumor growth, ecological competition, and sustainable harvesting. In order to study the behavior of these processes, students make use of a computer program that simulates the model's behavior. This is an example of substantive use: the program itself is object of study. Although these practical components have certain content-specific elements, almost all of them are aimed at the achievement of different general aspects of academic skills, such as hypothesizing and testing, data acquisition, analysis and interpretation, and modeling.

The second-level course on experimentation is quite similar to the first-level course didactically speaking. The new, extra, objectives for the second course on experimentation are on a higher level than for the first course (Table I, fourth column). We will turn to both courses on experimentation in more detail later in the article.

Following the second-level course on experimentation are the third-level courses, which again have sizable practical components in the form of IV and computer simulations. The difference between second- and third-level courses is that while secondlevel courses are at best multidisciplinary in nature, third-level courses try to achieve a certain degree of interdisciplinarity with respect to their content. The practicals used in these courses also take this approach. All these practical components are simulations of real-life situations. They are not carried out at traditional universities in wet laboratories and therefore do not fall under the heading of alternatives for wet laboratories, but students do learn practical skills by carrying out these simulations. Examples are the course on world food production, where a complete crop production system is simulated; the course on applied ecology: human and their ecosystems, in which an entire aquatic ecosystem is simulated; and the course on cleaner production, in which the focus is on integrated life-cycle management. In a simulation of such a management system, students can choose environmental and technical measures that influence the amount and nature of pollution and the costs of materials, and they have to weigh the pros and cons of each measure taken.

Finally, the diploma student starts a 800-hour research apprenticeship. This apprenticeship contains the following aspects, all of which have been practiced in the previous practicals:

- formulating a research question and a research proposal (how to solve the problem)

- planning the research

- carrying out the research proposed and gathering data

- interpreting and evaluating the results obtained as a basis for further research

- writing a report on the research carried out

- delivering an oral presentation of the results.

The research apprenticeship is usually not carried out at the OUN itself, but at different research centers (universities, institutes) throughout the country under the daily supervision of a researcher at that center and closely monitored by a staff member at the OUN. Depending on the student's background and specific interest, the apprenticeship can contain wet laboratory or can have a more theoretical nature and focus on literature research.

\section{Courses on Experimentation}

The decision has recently been made to revamp the different degree programs with respect to their use of wet practicals. The major feature of this modification is the elimination of three disciplinecentered laboratory practicals, for biology, chemistry, and physics of 50 hours each, and their replacement by two courses on experimentation of 100 hours each. The most important reason for this change was that it was debatable whether the time 
students spent attending three separate laboratory practicals was effectively and efficiently used. Indications for this criticism were:

- All three practicals were designed as introductions to a specific science discipline and were supposed to contribute to the attainment of certain discipline specific and nonspecific skills.

- The higher academic skills, such as hypothesizing, designing an experiment, solving problems, were not effectively handled in practicals organized this way.

- There was too little time within the three lab practicals for those learning objectives relating to what is done both prior to and subsequent to actual laboratory work.

- There was too little time to indicate that many practical objectives are common to all science disciplines. Because of this, these objectives are most probably not experienced as common by the students.

In all fairness, there are not only negative points to the use of this type of practical. Among the positive aspects noted when evaluating the laboratories were that attending a wet laboratory:

- livened up the theory,

- made the idea explicit that practical work is intrinsic to working in the natural sciences, and

- allowed students to meet and interact with other students.

We did not want to lose these positive things when rearranging the laboratory practicals.

Both courses on experimentation take place during holiday periods in laboratory facilities at traditional universities. The two courses have basically been set up in the same way. The point of departure for these two courses is the steps that can be recognized in the experimental cycle in natural sciences. The experimental cycle can be divided into three stages namely: the prelab, lab, and postlab stages. Closely bound up with these three stages are six general objectives which are fairly analogous to the successive steps in performing an experiment (Fig. 3). Each of these general objectives has, in turn, been subdivided into specific objectives (Table I) that describe what the student is able to do after finishing practical work (Kirschner and Meester, 1988).

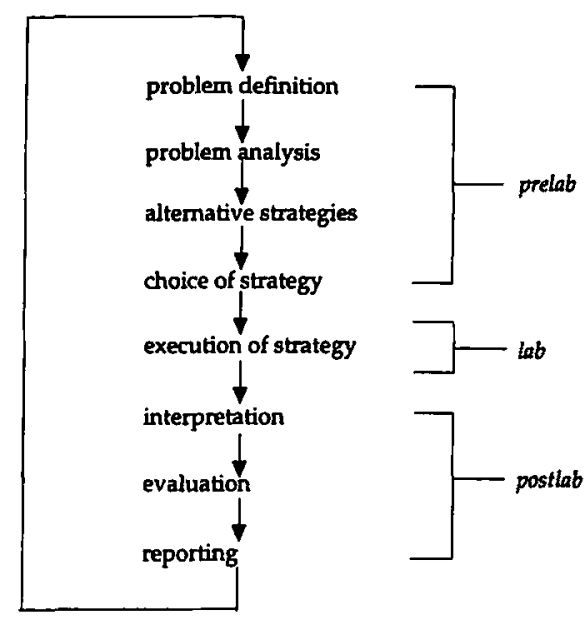

General abjectives:

A to solve problems

$B$ to use knowledge and skills in unfamiliar situations

C to design (simple) experiments to test hypotheses

D to use laboratory skills in performing (simple) experiments

$E$ to interpret experimental data

F to communicate about the experiment clearly

Fig. 3. Experimental cycle in natural sciences and the six general objectives A-F.

In an empirical evaluation study among faculty members (Kirschner et al., 1991), approximately 40 specific objectives were determined to be essential to science education at OUN. These objectives were categorized as to whether they represented basic skills or more advanced skills. The first-level course on experimentation pursues the basic skills (see the column with the heading First level, in Table I). The second-level course strives to achieve the higher academic skills while reinforcing and applying the lower-level skills (Table I).

The didactic methods used in the prelab stage of the first-level course involve the use of written materials for describing the experiments, their aims, and the methodology; simulation of practical skills for attaining those skills necessary for doing research; and an experimental seminar for achieving those skills endemic to analysis of and reflection upon what will be done or has been done. The written material and the simulations take place in a selfstudy context. The first-level course is focused on the theme of photosynthesis and on the external factors that affect it. The topic makes it possible to in- 
tegrate specific biological, chemical, and physical knowledge and skills on the one hand, while dealing with common skills related to doing research in all three fields on the other. This prelab stage, of approximately 20 study hours, concentrates on achieving those basic specific objectives that are categorized as belonging to general objectives to solve problems, to use knowledge and skills in unfamiliar situations, and to design (simple) experiments to test hypotheses. The lab stage, which involves a 60 -hour residential program, concentrates primarily on setting up and doing the experiments proposed in the plan and on gathering data. This laboratory work is interspersed with periods in which students, in an experimental seminar format, have the chance to discuss progress in and problems encountered with experimentation. These discussions could and should lead to larger and smaller adjustments in the experimental procedure. In this stage, the laboratory would be used for the acquisition of general objective to use laboratory skills in performing (simple) experiments, while the experimental seminar will make a start on helping students achieve general objective to interpret experimental data. The postlab stage of about 20 hours has primarily a self-study character, in which the students would be busy with the interpretation and evaluation of the experimental data. The first-level course ends with a written report containing a description of the research carried out and a proposal for further study and in that way achieving the general objective to communicate about the experiment clearly. This, in turn, is the beginning of a new iterative research cycle.

The second-level course has the same format as the first-level course, but the lab stage is less important than in the first-level course, as one can conclude from the amount of time available for the lab stages (45 hours versus 60 hours in the first-level course). The prelab stage ( 25 hours) here also involves the use of written materials, which makes the student familiar with some basic theories, concepts, and research methods in the field ecotoxicology. At the end of this stage, the student has to write a research proposal dealing with the effects of cadmium exposure on the energy budget of the isopod Porcellio scaber (wood-louse), in order to gain insight into mechanisms of adaptation to metal intake and possible effects of metal exposure on ecosystems. The lab stage, which involves a 45-hour residential program, starts with an experimental seminar in which the research proposals and the experimental contents of the course are discussed. Lectures to put the results achieved in a wider perspective are given in the evenings.

The postlab stage requires approximately 30 study hours. In this stage the student has to write a report-in the format of a scientific paper-containing an analysis and interpretation of the experimental results. This stage ends with a group session in the form of a symposium (experimental seminar), in which students get the chance to present their findings orally and discuss all aspects of the experimental process or cycle.

\section{EXAMPLES OF ALTERNATIVES FOR WET LABORATORY}

In this section some solutions are presented for replacing wet laboratories, field trips, or excursions along with their "wet" counterparts and their advantages and disadvantages. This will be done on the basis of examples from four OUN courses in the natural sciences.

\section{Biology of Populations and Behavior (Westerterp-Plantinga et al., 1987)}

The course (nominally 200 study hours) is subdivided into a 100-hour course on ecology and a 100hour course on ethology. The former is supported by computer simulation programs on population dynamics, population genetics, and natural selection, the latter with interactive laser disk programs on observation and analysis of behavior, animal conditioning experiments, function and evolution of behavior, and social behavior. Not all of the practicals are substitutions for wet laboratory work; only the ones indicated with a plus sign in Table II are.

In this biology course, two determinants played a role in choosing for alternative practicals. First, real-life practical work on these subjects is difficult because of the duration of time involved in the growth of plants and animals, genetic mutation, and behavior of animals. Second, observation and determination of animal behavior is very time intensive, costly, and cannot be easily accompanied by feedback and explanation when done in real-life situations. Although alternative forms of practicals are used for these experiments, all the data used in these programs are based on authentic experimental work. 
The students even compare their results with experts and receive feedback based upon the discrepancies.

In the program about population dynamics, the student has to verify the mathematical models for population growth that are presented in the printed course material. The student can also simulate the effects of factors that influence the environment. In a wet laboratory the student lets a population of test animals grow and experiments with them, mainly assessing their numbers. The main advantages of this program are that one can deal with a far larger population for statistical purposes, it is less boring (watching animals grow!), and costs less time and money.

The simulation program on population genetics deals with standard processes of genetics, such as selection, mutation, migration, drift, and the consequences of these processes on a population. Sorting out different species with typical characteristics is quite a job in a wet laboratory; the gain in time is enormous as well.

The third simulation program is on natural selection of a plant. Here it is necessary to grow several generations, which can be done in a wet laboratory (here a field experiment), but in a computer simulation the number of generations can be much larger, the feedback much more direct, and as a result the effects of natural selection are far clearer.

The first IV program, a replacement of a wet laboratory, is about the behavior of a stickleback in the sexual phase. The goals of this practical are a training in observation, learning to make a protocol of recognizable actions of behavior, and analysis of the data. In a traditional practical, students have to go to a laboratory and look for hours at an aquarium with sticklebacks. One of the problems for the students in a wet, traditional, laboratory is to clearly distinguish the different actions of fish behavior and protocol them, while in the IV program the student can display - with clear images - the actions of sexual behavior separately and evoke them again and again. One can also provide feedback on correct and incorrect classifications and compare both qualitative and quantitative results with an expert. Finally, the computer program can store the student's classifications so that he/she can see, when finished, whether he/she was right or wrong and, if the latter is the case, where he/she went wrong.

A second IV program on the stickleback is about conditioning the stickleback. One gives the stickleback some "good" and "bad" stimuli and watches the way the fish reacts to those stimuli and has its behavior conditioned. The wet experiment is possible but is difficult to set up and is very timeconsuming. The other six IV programs are similar to these two but deal with nesting behavior of gulls, social behavior of apes, and feeding behavior of starlings.

The advantages of IV and computer practicals versus the wet laboratory in this situation are:

- large quantities of data are more easily obtained, which facilitates statistical analysis,

- emphasis on specific actions of behavior without tutoring,

- easy repetition,

- immediate feedback,

- specific correction,

- increased number of trials,

- less boring.

Four general points that are valid for all practical alternatives are that students can study in their own pace and time, a teacher is not needed, these practicals cost less time for the student and cost less for the institute for exploitation (design and development, on the other hand, is relatively expensive).

Disadvantages of IV and computer practicals versus the wet laboratory are:

- little or no emotional involvement,

- lack of organizational and real-life constraints students have to cope with,

- lack of problems inherent to an experimental set up.

A general point that is valid for all practical alternatives (except for the experimental seminar) is that students do not learn from each other.

\section{Determination Practical about Toxicological Histopathology (Niesink et al., 1989)}

At the Open University of the Netherlands, two 100-hour courses in toxicology have been developed. The CD interactive (CD-I) disk about a histopathological practical forms part of these courses. This practical has been set up as a self-teaching program to learn basic analytical, synthetic, and evaluational skills of toxicological histopathology (and not of microscopy or staining!) without the help of a tutor. At traditional universities this practical is performed in a laboratory. The students have to prepare and study sections of organs or tissues through a microscope. In this alternative practical, 
Table I. Practical Components in Course on Biology of Populations and Behavior

\begin{tabular}{ll}
\hline \multicolumn{1}{c}{ Computer simulations } & \multicolumn{1}{c}{ N programs } \\
\hline Population dynamics $(+)$ & $\begin{array}{l}\text { Observation and analysis of } \\
\text { behavior }(+)\end{array}$ \\
Population genetic process $(+)$ & $\begin{array}{l}\text { Conditioning experiment }(+) \\
\text { Function and evolution of } \\
\text { behavior }(-)\end{array}$ \\
& Social behavior $(-)$ \\
\hline
\end{tabular}

${ }^{a}(+)$ means replacement of wet laboratory; ( - ) means no replacement of wet laboratory.

the microscope and sections have been replaced by a CD-I disk containing a large data base of slides of histopathological sections. The main difference encountered in working with this program is that all the actions required have been structured.

During the practical, the student is guided by a computer program and learns to recognize, localize, and characterize histopathological changes induced by man-made and natural agents. After an audiovisual introduction, the student gets access to different assignments in which basic analytic and evaluative skills are practiced and which are followed by more complex assignments. In each assignment at least one affected section is presented together with an unaffected control section. By comparing the sections, the student has to recognize the changes occurring in connection with a specific intoxication and the effects of dosage and time on changes. Students will not always be familiar with the phenomena they come across in the practical. In that case, they have access to an electronic, interactive reference book.

In the reference book, students can find magnifications of microscopic sections and textual information that can help them find the right answer to the questions in the practical. When students encounter an unfamiliar word or concept, they can also use the reference book via a hypertext situation and get a brief explanation, mostly in connection with a slide or magnification. Finally, the reference book can also be used on its own, for example, when a student is preparing for an examination. The reference book is organized and is accessible on the basis of tumor, organ, toxicant, pathology, and stain. In general students may choose their own way through the practical, depending on their interest and prior knowledge. The student can at all times access all parts of the package and shift easily from practical to reference. This is an important point because students on this course may have different backgrounds (medicine, biology, or chemistry).

The initial investment in order to develop such a practical in terms of time and money is considerable, but the cost of running the practical for several years is very low as compared to a traditional wet laboratory. However, this is not really a fair comparison, because one is dealing with two different learning situations with different objectives.

The advantages of this sort of practical versus a traditional microscope practical are that:

- students can follow this practical individually;

- students can study the practical in any order they wish;

- the program takes account of different levels of background knowledge;

- students can look at the same high-quality sections and at many more sections than in a lab practical;

- students can use several "microscopes" at the same time (up to seven different sections with two different stains and three different magnifications-in other words 42 different set-ups-which are instantaneously available) and can switch easily between them;

- artifacts such as bad slides, wrong staining techniques, etc., are eliminated, so the student can concentrate on the achievements of the higher-order cognitive skills;

- total cost-running over a number of years-is in general lower than that of a laboratory practical;

- gain in time.

Disadvantages are:

- students do not learn to use a microscope (but that is not an objective of this practical)

- students do not learn to prepare and stain sections themselves (also not an objective of the practical).

\section{A Geological Excursion through the Ardennes (Leinders et al., 1989)}

One of the various types of practical training in natural sciences at traditional universities, especially in the fields of geology and biology, involves excursions or field trips. Excursions are not included 
in the teaching program of the Open University of the Netherlands because they constrain the students as far as time, pace, and place and are, in this respect, difficult to organize. Furthermore excursions are quite costly (for the OUN itself as well as for the students) and cause a great number of logistical problems when relatively large numbers of students are involved.

Excursions and wet laboratories have in common that at least part of their learning objectives is focused on the training in certain kills. A simulation of an excursion by means of an interactive video disk (or CD-I) is not a replacement of a real excursion in the field. However, it has its own intrinsic value, just as a field trip has its own value.

At the OUN two courses on geology have been developed, both are 100-hour courses: one dealing with plate tectonics and one with ice ages. A simulation of a field trip to the Ardennes is part of the first course and takes about ten study hours. The Ardennes is a mountainous area in Belgium just south of the Netherlands. The main goals of the geological excursion are, via a visit to a number of sites, to compare the field situation with geological maps and time scales and to determine the geological history of the sites. Due to the fact that the geographic distribution of these exposures is at random, it is not possible in a field excursion to visit the various localities in a logical order because of transportation and logistical problems. In the IV excursion, it is possible to reconstruct the almost 600 -million-year geological history of the Ardennes, step by step from the oldest rock formations to the youngest ones. Furthermore, the systematic way in which an exposure of rock must be investigated can be trained more effectively by computer than in a real excursion, which is always, at least slightly, chaotic.

On the other hand, chaos and random presentation of data are part of real life and a student should also be trained in handling such situations. In a real excursion, a student will more easily be confronted with less-than-ideal circumstances for making objective observations, such as bad weather, tiredness, bad rock exposures, unknown phenomena, etc. When we consider the learning objectives of a geological excursion and indicate with a plus if the objective is more easily achieved with an IV excursion, with a minus if it is more difficult to achieve, and with plus/minus if it does not make any difference, then the results are quite amazing. Most ob- jectives are achieved to the same extent or better in the IV excursion than in the field excursion.

Learning objectives of field excursion are to:

- get practical experience in the way geological field data are collected (-)

- get practical experience in the way geological field data are interpreted $( \pm)$

- get insight into the way the geological history of an area can be reconstructed (t)

- learn basic skills: simple field experiments in order to distinguish minerals, recognizing typical fossils, and structural aspects in order to distinguish sediments $( \pm)$

- learn to use and "read" geological maps $(t)$

Advantages of IV excursion versus field excursion are:

- students can visit the places of interest in chronological order

- students can investigate the exposure of a rock in a systematic way

- students can start the excursion any time they want to

- students can visit the same places again and again (to compare and contrast)

- the excursion is independent of the number of students

- students easily get feedback that is independent of tutors

- most learning objectives are achieved to the same extent or better than in a real excursion

- the excursion is independent of the weather

- it is cheaper for the institute as well as for the students

- gain in time: ten hours versus four days

- the excursion is independent of teacher

- it is easier to organize (students do not have to use their vacations, etc., to follow this practical).

Disadvantages are:

- students are used to ideal circumstances: good weather, nice pictures, etc.

- students do not learn to abstract from reallife situations (real rocks are rather different from a picture or slide on the monitor)

- students do not get a tacit knowledge of phenomena (Fingerspitzengefühl-smell, roughness of the stone, hardness, tempera- 
ture, etc.). This can, however, be solved by using a sample kit or box.

- the excursion is limited by the availability of hardware (video disk players or CD-I equipment).

One might conclude that in the case of an excursion, a didactic optimum can be reached by combining a computer simulation with a real field excursion. In that way the efficiency and effectiveness of the field excursion will be largely improved.

\section{Remote Sensing: An Interactive Video Disk or CD-ROM Disk (Leinders et al., 1992)}

An interactive CD-ROM disk is the practical component of the course on remote sensing. The total course is programmed for 100 study hours: 90 hours for the written material and ten hours for the practical. The term remote sensing implies techniques that mimic human sensory perception from a distance, not only in the visible spectrum of human beings, but also in the near- and far-infrared, ultraviolet, radar, etc. The sensors of satellites send the remotely sensed information in digital form to receiving stations on earth. The data are manipulated by computers and by means of various image-processing techniques to optimize their information content. These transformed data can then be easily interpreted by the more visually oriented human beings. An image is a nearly continuous record of the properties of an object displayed as a variation of light intensities in two dimensions.

The CD-I based practical consists of five case studies based on environmental applications, such as phytoplankton in the Arabian Sea and North Sea thermal pollution. Since the original data is stored in digital format on the CD-ROM, it is possible for the students to do real, on-line-image processing. This is an example of a substantive use of a computer program. Actually, this practical is exactly the same as the practical of a traditional course in remote sensing. However, it differs from a traditional course because of the built-in tutor. The CD-ROM can function as a stand-alone educational item for the students without the need of the presence of a teacher. Furthermore, the student/teacher is not dependent upon arbitrary information obtained from the satellites, but can make use of stored, specifically chosen materials, and aimed at the achievement of specific goals.

\section{CONCLUSIONS}

Laboratory work is not the same as alternative practical forms. Students always miss some things or do not achieve some aims (in particular manipulative skills), but more often than not students gain a lot of other things and achieve some other aims. However, comparing a wet laboratory or a field trip at traditional universities with a simulation at the Open University of the Netherlands is not really a fair comparison, because one compares two different learning settings often meant to achieve different objectives within two different types of degree programs in the natural sciences. In the case of the OUN, where a wet laboratory is not always a real possibility, CAI, IV, CD-I, or CD-ROM can often be viable alternatives.

Although it is quite normal to assume that undergraduate students in the natural sciences will spend a great deal of time working in wet laboratories, this is not the case for students studying at the OUN. This is not because the OUN thinks that practicals lack educational value, but rather because it is trying to educate a different type of natural scientist (more multidisciplinary in nature than monodisciplinary) in a different educational system (open distance education versus contact education) than most other institutes of higher education. The result of these two differences is that the OUN attempts to educate a different type of student to become a different type of scientist whose skills are different from other types of natural scientists.

Our graduates have to be able to analyze, synthesize, and evaluate results in order to apply the results in comparable or different situations. Practicals, if they are designed properly, can play an important role in achieving those aims. The Open University of the Netherlands is trying to find out whether this is feasible.

\section{REFERENCES}

Clackson, S. G., and Wright, D. K. (1992). An appraisal of practical work in science education. School Science Review 74: 39-42.

Conway, R. G., Mendoza, E., and Read, F. H. (1963). The seminar method of teaching experimental physics. Bulletin of the Institute of Physical Society 14: 330-332.

Hodson, D. (1988). Experiments in science and science teaching. Educational Philosophy and Theory 20: 53-66.

Hodson, D. (1992). Redefining and reorienting practical work in school science. School Science Review 73: 65-78. 
Hofstein, A, and Lunetta, V. N. (1982). The role of the laboratory in science teaching: Neglected aspects of research. Review of Educational Research 52: 201-217.

Huisman, W., and De Vries, F. (1991). Functions and design of educational simulation programs. Report, Centre for Educational Technology, Heerlen: Open universiteit.

Kirschner, P. A. (1992). Practicals in Higher Education, Lemma, Utrecht.

Kirschner, P. A., and Meester, M. A. M. (1988). The laboratory in higher science education: problems, premises and objectives. Higher Education 17: 81-98.

Kirschner, P. A., Meester, M. A. M., and Middelbeek, E. M. (1991). Practical objectives at the Open University of the Netherlands. Journal of Distance Education VI: 5-27.

Leinders, J. J. M., Beyderwellen, W., Wigman, M. C. S., and Smit, O. E. (1989). Plate tectonics, Open University of the Netherlands, Heerlen.

Leinders, J. J. M., Drury, S. A., Rothery, D. A., Kirschner, P. A., Beyderwellen, W., and Smit, O. E. (1992). Remote sensing, Open University of the Netherlands, Heerlen.

Moore, C., Smith, S., and Avner, R. A. (1980). Facilitation of laboratory performance through CAI. Journal of Chemical Education 57: 196-198.
Nota open unversiteiten in Nederland [Policy paper open universities in the Netherlands]. (1979). Lower House of Parliament, session 1978-1979, 14400, nrs. 3-4, The Hague: Staatsuitgeveriji.

Niesink, R. J. M., Drijver-DeHaas, J. S., Kirschner, P. A., and DeVries, F. J. (1989). General Taxicology 2, Open University of the Netherlands, Heerlen.

Toothacker, W. S. (1983). A critical look at introductory laboratory instruction. American Journal of Physics 51: 516-520.

Westerterp-Plantenga, M. S., Van Bon, J., Brunsting, A. M., Van Dijk, H., Hols-Elders, W. P. M., Huisman, W., Jonker, A., Kirschner, P. A., and Van Rhijn, J. G. (1987). Biology of Populations and Behavior, Open University of the Netherlands, Heerlen.

Wolf, H. C. de. (1985). Open onderwijs of de voortdurende beweging can lerende mensen [Open education of the constant movement of people learning]. Inaugural lecture on the acceptance of the position of professor in the theory and history of education. Samson uitgeverij bv, Alphen aan de Rijn. 